\title{
Meisenheimer Complexes from 1,3,5-Trinitrobenzene, tert-Butyl Isocyanide and Copper
}

\author{
ANNA-TORA HANSSON and MARTIN NILSSON
}

Department of Organic Chemistry, Chalmers University of Technology and University of Göteborg, S-41296 Göteborg, Sweden

Meisenheimer type compounds are formed when 1,3,5-trinitrobenzene reacts with tert-butyl isocyanide and copper(I) oxide or metallic copper. Ylide structures in which the isocyanide carbon is attached to the $s p^{3}$ carbon of the 2,4,6-trinitrocyclohexadienide ion are suggested.

Donor-acceptor complexes are formed between 1,3,5-trinitrobenzene and tert-butyl isocyanide and between 1,3,5-trinitrobenzene, copper(I) chloride and tert-butyl isocyanide.

Several organocopper reactions and reactions of copper(I) oxide with organic substrates are promoted by soft bases such as pyridine, ${ }^{1}$ quinoline ${ }^{2}$ and isocyanides. ${ }^{3}$ Pyridine promotes addition of organocopper ${ }^{4}$ or organosilver compounds ${ }^{5,6}$ to 1,3,5-trinitrobenzene to form Meisenheimer compounds. Isocyanide-copper complexes have proved to be useful in addition reactions to electron-poor olefins. ${ }^{7}$ Isocyanides add to the $\beta$-carbon of $\alpha$-nitroolefins. $^{8}$

We now report some reactions between 1,3,5trinitrobenzene, tert-butyl isocyanide and copper(I) oxide or metallic copper. The structural interpretations are still somewhat uncertain. However, some of the results seem relevant to the general problem of catalysis by copper and soft bases.

\section{RESULTS}

The reaction between 1,3,5-trinitrobenzene (TNB), copper(I) oxide $\left(\mathrm{Cu}_{2} \mathrm{O}\right)$, and tert-butyl isocyanide in benzene gives a red, crystalline complex (A). The visible spectrum with strong absorptions at $434(\varepsilon=27000)$ and $525 \mathrm{~nm}(\varepsilon=15000)$ indicates a Meisenheimer compound (1). The infrared spectrum of the solid shows typical absorption around $1200 \mathrm{~cm}^{-1}$ and one sharp line in the isocyanide region $\left(2186 \mathrm{~cm}^{-1}\right)$.

Complex A is labile. It gives off tert-butyl isocyanide and dissociates on standing. This makes the interpretation of the analytical results somewhat uncertain. However, together with ${ }^{1} \mathrm{H}$ NMR integrals they show that complex A contains the components in the molar proportions 2:1:8. It also retains $0.33 \mathrm{~mol}$ benzene of crystallization per mol TNB (cf. Refs. 9 and 10). Complex A dissociates in solution, the measured extinction values above are therefore probably too low, even though an excess of tert-butyl isocyanide was used to suppress the dissociation.

The ${ }^{1} \mathrm{H}$ NMR spectrum of a fresh chloroform- $d$ solution of complex A shows the resonances of $\mathrm{H}^{\mathrm{a}}$ and $\mathrm{H}^{\mathrm{b}}$ at lower fields than are usual in Meisenheimer compounds ( $c f$. Table 1 and Ref. 11), and one tert-butyl signal. ${ }^{1} \mathrm{H}$ NMR spectra for a dichloromethane- $d_{2}$ solution down to $173 \mathrm{~K}$ show a single tert-butyl signal at $\delta 1.50$.

The ${ }^{1} \mathrm{H}$ NMR spectrum of a chloroform- $d$ solution of complex A changes with time and shows that an exchange takes place with the formation of the known ${ }^{12}$ 1-trichloromethyl-2,4,6-trinitrocyclohexadienide anion $(\mathrm{C})$ in $60 \%$ yield. For dimethyl sulfoxide- $d_{6}$ and acetone- $d_{6}$ solutions only ${ }^{1} \mathrm{H}$ NMR spectra for the known 1-hydroxy-2,4,6trinitrocyclohexadienide anion (D) are observed (Table 1). This ion is apparently formed by water present in the solvents. Similar observations have been described by others. ${ }^{13}$

A crystalline Meisenheimer complex (B) is also formed rapidly from 1,3,5-trinitrobenzene, metallic 
Table 1. ${ }^{1} \mathrm{H}$ NMR $(270 \mathrm{MHz})$ data for the Meisenheimer complexes. The chemical shifts are given in $\delta$ values, and the number of protons in parantheses. The experiments are normally run at room temperature $(296-300 \mathrm{~K})$. Spectra of $\mathrm{A}$ and $\mathrm{B}$ at room temperature show a small, but growing peak at $\delta 9.37$ $\left(\mathrm{CDCl}_{3}\right.$ or $\left.\mathrm{CD}_{2} \mathrm{Cl}_{2}\right)$ due to "free TNB". s, singlet; m, multiplet.

\begin{tabular}{|c|c|c|c|c|c|c|c|c|}
\hline Complex & Solvent & $\frac{\mathrm{H}^{\mathrm{a}}}{(2) \mathrm{s}}$ & $\frac{\mathrm{H}^{\mathrm{b}}}{(1) \mathrm{s}}$ & $\mathrm{H}^{\mathrm{c}}$ & $\mathrm{H}^{\mathrm{d}}$ & $\mathrm{H}^{\mathrm{e}}$ & $\frac{\mathrm{H}^{t-\mathrm{Bu}}}{\mathrm{S}}$ & $\frac{\mathrm{H}^{\text {benzene }}}{\mathrm{S}}$ \\
\hline A & $\mathrm{CDCl}_{3}$ & 8.72 & 6.67 & & & & $1.51(36)$ & $7.35(2)$ \\
\hline A & Benzene- $d_{6}$ & 8.38 & 6.34 & & & & 0.96 & 7.17 \\
\hline A & $\mathrm{CD}_{2} \mathrm{Cl}_{2}{ }^{a}$ & 8.57 & 6.55 & & & & $1.50(36)$ & 7.36 \\
\hline A & $\mathrm{CD}_{2} \mathrm{Cl}_{2}{ }^{b}$ & 8.63 & 6.55 & & & & 1.50 & 7.44 \\
\hline B & $\mathrm{CDCl}_{3}$ & 8.71 & 6.67 & & & & $1.51(45)$ & 7.35 \\
\hline B & $\mathrm{CD}_{2} \mathrm{Cl}_{2}{ }^{a}$ & 8.53 & 6.52 & & & & $1.50(45)$ & 7.36 \\
\hline B & $\mathrm{CD}_{2} \mathrm{Cl}_{2}{ }^{c}$ & 8.55 & 6.50 & & & & 1.50 & 7.40 \\
\hline $\mathrm{C}$ & $\mathrm{CDCl}_{3}$ & 8.85 & 6.53 & & & & 1.51 & 7.35 \\
\hline D & DMSO $-d_{6}$ & 8.42 & 6.27 & 5.6 & & & 1.55 & 7.37 \\
\hline D & Acetone- $d_{6}$ & 8.54 & 6.52 & 4.4 & & & 1.55 & 7.37 \\
\hline $\mathrm{E}^{d}$ & $\mathrm{CDCl}_{3}$ & $\begin{array}{l}8.63 \\
8.65\end{array}$ & $\begin{array}{l}5.72, \\
5.75\end{array}$ & $\begin{array}{l}2.82(1) \mathrm{s} \\
3.05(1) \mathrm{s}\end{array}$ & $6.1-6.6(3) \mathrm{m}$ & & $1.50(36)$ & - \\
\hline$F$ & $\mathrm{CDCl}_{3}$ & 8.72 & 6.00 & $6.45(1) \mathrm{s}$ & $3.13(2) \mathrm{s}$ & $7.0-7.8(4) \mathrm{m}$ & $1.49(36)$ & - \\
\hline
\end{tabular}

${ }^{a} 273 \mathrm{~K}$, no signal in the TNB region. ${ }^{b} 193 \mathrm{~K}, \delta 9.55(2) \mathrm{s} .{ }^{c} 193 \mathrm{~K}, \delta 9.55(6) \mathrm{s} .{ }^{d}$ The expected isomers are formed in the proportions $1: 1$.

copper and tert-butyl isocyanide in benzene. It contains the components in the molar proportions $1: 1: 5$ and benzene of crystallization $(0.33$ mol per mol TNB). Complex B decomposes more readily than complex $\mathrm{A}$. The ${ }^{1} \mathrm{H}$ NMR spectrum of complex $\mathrm{B}$ in chloroform- $d$ shows that complex $\mathrm{B}$ is also converted to complex $\mathrm{C}$, but more slowly than $\mathrm{A}$.

The ${ }^{13} \mathrm{C}$ NMR spectra ${ }^{14}$ in chloroform-d of complexes $\mathrm{A}$ and $\mathrm{B}$ confirm the R-group exchange but are of no further help in the elucidation of the structures.

Treatment of complex A or B with cyclopentadiene or indene gives the known ${ }^{6}$ Meisenheimer complexes $\mathrm{E}$ and $\mathrm{F}$. The reaction is slower for complex $B$ and then occurs with evolution of a gas, presumably hydrogen.

Treatment of solid complex A with $1 \mathrm{M}$ hydrochloric acid gives a yellow solid (complex G). The same complex is formed with gas evolution from complex $B$ and hydrochloric acid. Complex $G$ is also formed from 1,3,5-trinitrobenzene, copper(I) chloride and tert-butyl isocyanide. The complex G absorbs at a $20 \mathrm{~nm}$ longer wavelength than does TNB, with an extinction coefficient four times higher than that for TNB. ${ }^{1} \mathrm{H}$ NMR shows the ratio TNB to isocyanide to be $1: 4$.

Treatment of complex $G$ with excess of tertbutyl isocyanide precipitates a complex between
copper(I) chloride and tert-butyl isocyanide ${ }^{15}$ while the solution turns red. The mother liquor on concentration until the residue does not smell of tert-butyl isocyanide, gives a red oil containing TNB and isocyanide in the molar proportions 1:2 (cf. Ref. 16). The ${ }^{1} \mathrm{H}$ NMR data and the visible spectrum with a moderate absorption at $495 \mathrm{~nm}$ indicate a charge-transfer complex between TNB and tert-butyl isocyanide. This complex is also formed directly from the components. The ${ }^{1} \mathrm{H}$ NMR spectra of complex A or B below $223 \mathrm{~K}$ in dichloromethane- $d_{2}$ show a peak at $\delta 9.55$; this is at a lower field than normal for TNB and could be due to TNB in a charge transfer complex. ${ }^{17}$

\section{DISCUSSION}

1,3,5-Trinitrobenzene is a classical reagent both in donor-acceptor chemistry and in the chemistry of Meisenheimer compounds.

We have noted above the formation of a donoracceptor complex $(t-\mathrm{BuNC})_{2}$ TNB. The strength of the interaction is shown by the change in the IR absorption frequency for the isocyanide, $(\Delta v=+40$ $\mathrm{cm}^{-1}$ on complexation, compared with free tertbutyl isocyanide). For complex $\mathrm{G}\left(\Delta v=+35 \mathrm{~cm}^{-1}\right)$ and copper(I) chloride - tert-butyl isocyanide $(\Delta v=$ 
$+50 \mathrm{~cm}^{-1}$ ) the IR absorption frequencies are also increased. The copper or copper(I) oxide-isocyanide reagents which have been used for preparative purposes have not been fully characterized but show $\Delta v=+40 \mathrm{~cm}^{-1} \cdot{ }^{18}$ In complexes $\mathrm{A}$ and $\mathrm{B}$ we therefore conclude that the interactions between copper(0) or copper(I) oxide and isocyanide are comparable to those between TNB and isocyanide.

In the ternary system TNB, isocyanide and copper(I) oxide or copper(0) these interactions could compete. However, we find that copper promotes the formation of a $\sigma$ bond to TNB (1) to give complexes A and B. Their reactivities, however,

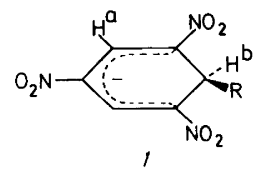

complicate the strict assignment of the group $\mathbf{R}$ in 1 . This group must be common to complexes $A$ and $\mathrm{B}$ and we propose $\mathrm{R}-=t$-BuNC- as the most probable (2). This ylide structure would explain the low resonance fields for $\mathrm{H}^{\mathrm{a}}$ and $\mathrm{H}^{\mathrm{b}}$ (Table 1) in ${ }^{1} \mathrm{H}$ NMR. Similar ylide intermediates have been proposed in reactions between isocyanides and $\alpha, \beta$ unsaturated carbonyl ${ }^{8}$ or nitro compounds ${ }^{19}$ (3).

One would have expected separate NMR signals for the tert-butyl group in $\sigma$-bonded and copperbonded isocyanide. However, in all complexes

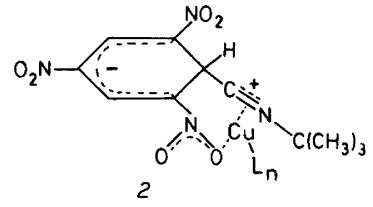

$\mathrm{R}-\mathrm{N}=\dot{\mathrm{C}}-\mathrm{CH}_{2}-\overline{\mathrm{C}} \mathrm{H}-\mathrm{X} \quad \mathrm{X}=\mathrm{NO}_{2}, \mathrm{COOCH}_{3}$

3

described here only one sharp tert-butyl signal is observed. The long range ${ }^{14} \mathrm{~N}-{ }^{1} \mathrm{H}$ coupling which is seen in free tert-butyl isocyanide ${ }^{20}$ is absent in complexes $\mathrm{A}-\mathrm{G}$ (cf. Refs. 10, 21). This indicates quadrupole relaxation processes due to exchange of tert-butyl isocyanide between metal atoms or between metal atoms and TNB. ${ }^{21}$

The unsaturated carbon - nitrogen bond of the ylide provides possibilities of coordination of copper. The copper could be coordinated also by a nitro-group in the ring. The bonding could be compared to that in imines formed by insertion of isocyanide into the copper - carbon bond of arylcopper(I) compounds. ${ }^{22}$

One may speculate on the reactions of the ylides. Addition of nucleophile to the isocyanide carbon, or addition of a copper compound such as copper(I) trichloromethanide $\left(4, \mathrm{R}=\mathrm{CCl}_{3}-\right)$, might give an intermediate (5) for formation of a new Meisenheimer complex (6) by $\alpha$-elimination (Scheme 1).

$$
\begin{aligned}
& \left.\left.\mathrm{Cu}_{2} \mathrm{O}\left[\mathrm{CNClCH}_{3}\right)_{3}\right]_{\mathrm{n}}+2 \mathrm{RH} \longrightarrow \underset{4}{2 \mathrm{RCu}}\left[\mathrm{CNClCH}_{3}\right)_{3}\right]_{\mathrm{m}}+\mathrm{H}_{2} \mathrm{O} \\
& 2 \mathrm{Cu}\left[\mathrm{CNC}\left(\mathrm{CH}_{3}\right)_{3}\right]_{\mathrm{n}}+2 \mathrm{RH} \longrightarrow \underset{4}{2 \mathrm{RCu}}\left[\mathrm{CNC}\left(\mathrm{CH}_{3}\right)_{3}\right]_{\mathrm{m}}+\mathrm{H}_{2}
\end{aligned}
$$
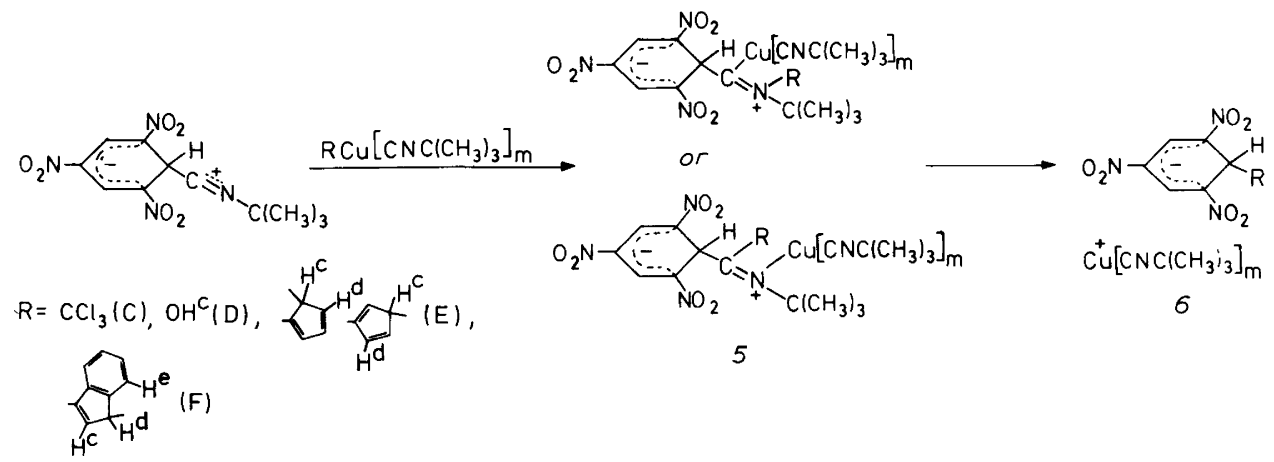

Scheme 1.

Acta Chem. Scand. B 34 (1980) No. 2 
If so, complexes A and B would be interesting examples of catalytic intermediates, just as the pyridine Meisenheimer intermediate in the silver oxide-promoted addition of indene to TNB. ${ }^{6}$

However, the $\sigma$-complexes $\mathrm{C}, \mathrm{D}, \mathrm{E}$ and $\mathrm{F}$ may also be formed by direct reaction ${ }^{23}$ between TNB and the nucleophile, and organocopper(I) isocyanide complex. A cyclopentadienylcopperisocyanide complex and an indenylcopper-isocyanide complex ${ }^{22}$ could be the intermediates in the fast formation of 1-cyclopentadienyl-2,4,6-trinitrocyclohexadienide and 1-indenyl-2,4,6-trinitrocyclohexadienide, respectively.

In spite of the beauty of the red, needle-shaped crystals, the lability of complexes A and B has not allowed us, so far, to carry out further experiments to establish the structure of the complexes.

\section{EXPERIMENTAL}

Complex A. 1,3,5-Trinitrobenzene (10 mmol) was dissolved in benzene $(200 \mathrm{ml})$. Copper(I) oxide $(5$ $\mathrm{mmol})$ and tert-butyl isocyanide $25(40 \mathrm{mmol})$ were added and the mixture was stirred at room temperature. The copper(I) oxide slowly dissolved and after about $3 \mathrm{~h}$ a deep-red solid had precipitated. The solid was filtered off and washed with benzene to give $5.4 \mathrm{~g}$ of crude product. One gram was rapidly dissolved in $100 \mathrm{ml}$ benzene at $70{ }^{\circ} \mathrm{C}$ and the solution was filtered. The filtrate on standing gave red needles (0.6 g), m.p. $104-106{ }^{\circ} \mathrm{C}$ (decomp.). The melt resolidified at $195-198{ }^{\circ} \mathrm{C}$, possibly because of polymerisation of the tert-butyl isocyanide. ${ }^{13,18}$ Found: C 50.7; H 6.7; N 15.2; Cu 10.1. Calc. for $\mathrm{C}_{56} \mathrm{H}_{82} \mathrm{~N}_{14} \mathrm{O}_{13} \mathrm{Cu}_{2}$ (corresponds to trinitrobenzene-copper(I) oxide-tert-butyl isocyanide in the proportions $2: 1: 8$ plus $2 / 3$ benzene of crystallization): $\mathrm{C} 52.5 ; \mathrm{H} 6.1 ; \mathrm{N} 15.3$; $\mathrm{Cu} 9.9$. VS in benzene with excess of tert-butyl isocyanide $(\log \varepsilon)$ : $434(4.443), 525(4.176) \mathrm{nm}$. The extinction coefficients were calculated per "TNB-unit". When samples were withdrawn from the reaction mixture and not exposed to the air, two other absorption pairs were transiently observed during the reaction at 465 and $575 \mathrm{~nm}$ and at 480 and $610 \mathrm{~nm}$ of intensities comparable to those above.

VS of $A$ in acetone $(\log \varepsilon)$ : After $1 \mathrm{~min} 435$ (4.248) and $515 \mathrm{~nm}$ (4.088) (complex A) and 462 (4.062) and 570 (sh, 3.30); after $20 \mathrm{~min} 462$ (4.434) and 570 (3.945). The second absorption pair is due to the formed 1-hydroxy-2,4,6-trinitrocyclohexadienide ion in complex D. IR (KBr): 1510, 1245 (b), 1200, $1055 \mathrm{~cm}^{-1}$ (Meisenheimer compound) and 2186 $\mathrm{cm}^{-1}$ (s, isocyanide). ${ }^{1} \mathrm{H}$ NMR $(270 \mathrm{MHz}$, benzene$\left.d_{6}\right) \delta 8.38\left(\mathrm{H}^{\mathrm{a}}, 2 \mathrm{H}, \mathrm{s}\right), 6.34\left(\mathrm{H}^{\mathrm{b}}, 1 \mathrm{H}, \mathrm{s}\right), 0.96\left(\mathrm{H}^{t-\text { butyl }}\right.$,
$36 \mathrm{H}, \mathrm{s})$. For further details and other solvents see Table $1 .{ }^{13} \mathrm{C}$ NMR $\left(67.88 \mathrm{MHz}, \mathrm{CDCl}_{3}\right): \delta 151$ $(\mathrm{C} \equiv \mathrm{N}$, free isocyanide), $138(\mathrm{Cu}, \mathrm{C} \equiv \mathrm{N}), 125-132$ $\left(\mathrm{C}-\mathrm{NO}_{2}\right), 130\left(\mathrm{C}-\mathrm{H}^{\mathrm{a}}\right), 76.6\left(\mathrm{C}-\mathrm{H}^{\mathrm{b}}(\mathrm{C})\right), 58\left(\mathrm{C}-\mathrm{H}^{\mathrm{b}}\right.$ (A) disappearing), $56.2 \mathrm{C}-\left(\mathrm{CH}_{3}\right)_{3}, 31.0\left(\mathrm{C} \equiv \mathrm{H}_{3}\right)$. (Cf. Refs. 14 and 26.)

Complex B. Copper ${ }^{27}$ (2 mmol) was stirred in benzene $(15 \mathrm{mmol})$ and tert-butyl isocyanide (10 mmol) was added under nitrogen. The copper dissolved and a white precipitate appeared. When solid 1,3,5-trinitrobenzene $(2 \mathrm{mmol})$ was added, red crystals precipitated immediately. A yield of $1.0 \mathrm{~g}$ $(53 \%)$ was recovered after recrystallization from benzene m.p. $107-109^{\circ} \mathrm{C}$ (decomp.). VS in benzene with excess of tert-butyl isocyanide $(\log \varepsilon): 434$ $(4,443), 525(4.176) \mathrm{nm}$. IR (KBr): 1510 (s), 1245 (b), 1200 (b), 1055 (m) $\mathrm{cm}^{-1}$ (Meisenheimer compound), $2186(\mathrm{~s}) \mathrm{cm}^{-1}$ (isocyanide). ${ }^{1} \mathrm{H}$ NMR ( 270 $\left.\mathrm{MHz} \mathrm{CDCl}_{3}\right): \delta 8.71\left(\mathrm{H}^{\mathrm{a}}, 2 \mathrm{H}, \mathrm{s}\right), 7.4$ (benzene, $2 \mathrm{H}$, s), $\left.6.68 \mathrm{H}^{\mathrm{b}}, 1 \mathrm{H}, \mathrm{s}\right), 1.51\left(\mathrm{H}^{t-\text { butyl }}, 45 \mathrm{H}, \mathrm{s}\right) .{ }^{13} \mathrm{C} \mathrm{NMR}$ $\left(67.88 \mathrm{MHz}, \mathrm{CDCl}_{3}\right): \delta 138(\mathrm{Cu}, \mathrm{C} \equiv \mathrm{N}), 125-130$ $\left(\mathrm{C}-\mathrm{NO}_{2}\right), 129.7\left(\mathrm{C}-\mathrm{H}^{\mathrm{a}}\right), 128.4$ (benzene), 124.2 $\left(\mathrm{C}-\mathrm{NO}_{2}\right.$ para $), 77.4\left(\mathrm{C}-\mathrm{H}^{\mathrm{b}}(\mathrm{C})\right), 56.9\left(\mathrm{C}-\mathrm{H}^{\mathrm{b}}(\mathrm{A})\right.$ disappearing), $55.2 \mathrm{C}-\left(\mathrm{CH}_{3}\right)_{3}, 30.3\left(\mathrm{C} \equiv \mathrm{H}_{3}\right)$ (cf. Refs. 14 and 26). Since the complex gives off isocyanide and decomposes within a few days under nitrogen it was not possible to obtain an adequate elemental analysis.

Copper tetra-tert-butyl isocyanide 1-cyclopentadienyl-2,4,6-trinitrocyclohexadienide (complex E). 1,3,5-Trinitrobenzene $(1 \mathrm{mmol})$ was dissolved in benzene $(50 \mathrm{ml})$, and copper(I) oxide $(0.5 \mathrm{mmol})$, tert-butyl isocyanide $(2 \mathrm{mmol})$ and cyclopentadiene $(10 \mathrm{ml}$, freshly distilled) were added. Immediately the mixture turned dark red and crystals precipitated when the solution was left in a refrigerator overnight. They were recrystallized from benzene, yield $0.31 \mathrm{~g}$ $(42 \%)$, m.p. $141-142{ }^{\circ} \mathrm{C}$.

The cyclopentadienyl $\sigma$-complex could also be prepared by addition of excess of cyclopentadiene to a saturated benzene solution of complex A or B, but the yield was lower.

Found: C 56.0; $\mathrm{H} \mathrm{7.0;} \mathrm{N} \mathrm{14.6;} \mathrm{Cu} \mathrm{9.4.} \mathrm{Calc.} \mathrm{for}$ $\mathrm{C}_{31} \mathrm{H}_{44} \mathrm{O}_{6} \mathrm{~N}_{7} \mathrm{Cu}$ : C 55.3; $\mathrm{H}$ 6.5; N 14.3; Cu 9.4. VS benzene $(\log \varepsilon): 472$ (4.443), $560(4.146) \mathrm{nm}$. IR $(\mathrm{KBr}): 2180(\mathrm{~m}$, isocyanide), $1200(\mathrm{vb}), 1045(\mathrm{~m})$ $\mathrm{cm}^{-1}$. The ${ }^{1} \mathrm{H}$ NMR data (Table 1 ) are analogous to those in Ref. 6 and show the expected cyclopentadienyl isomers in ratio $(1: 1)$.

Copper tetra-tert-butyl isocyanide 1-indenyl-2,4,6trinitrocyclohexadienide (complex $F$ ). 1,3,5-Trinitrobenzene $(1 \mathrm{mmol})$ was dissolved in benzene $(50 \mathrm{ml})$, and copper(I) oxide $(0.5 \mathrm{mmol})$, tert-butyl isocyanide ( $2 \mathrm{mmol})$ and indene $(2 \mathrm{mmol})$ were added, and the mixture became dark-red immediately. When the visible spectrum showed that the reaction was complete, hexane was added to precipitate the complex. The precipitate also retained a small 
amount of complex A. The crude product was dissolved in benzene and shaken with $1 \mathrm{M}$ hydrochloric acid to destroy complex A before complex $\mathrm{F}$ was recrystallized from benzene - hexane. Yield $0.54 \mathrm{~g}$ $(66 \%)$, m.p. $88-90{ }^{\circ} \mathrm{C}$. Found: C 54.0 ; H 6.0; $\mathrm{N}$ 13.0. Calc. for $\mathrm{C}_{35} \mathrm{H}_{48} \mathrm{O}_{6} \mathrm{~N}_{7} \mathrm{Cu}$ : C 53.8; $\mathrm{H}$ 5.0; $\mathrm{N}$ 12.6. VS benzene $(\log \varepsilon): 470$ (4.477), 542 (4.176) $\mathrm{nm}$. IR (KBr): $2190(\mathrm{~s}), 1200(\mathrm{vb}), 1040(\mathrm{~m}) \mathrm{cm}^{-1}$. The ${ }^{1}$ H NMR data (Table 1) are analogous to Ref. 6.

Complex $G$. When excess of $1 \mathrm{M}$ hydrochloric acid was added to complex A the red colour disappeared and the solid phase turned yellow. The same phenomena occurred under gas evolution when complex B was treated with $1 \mathrm{M}$ hydrochloric acid. The same compound was also formed from trinitrobenzene, copper(I) chloride and tert-butyl isocyanide in proportions $1: 1: \geq 4$, or from trinitrobenzene and copper(I) chloride - tert-butyl isocyanide complex in the proportions 1:1 in benzene. On standing, the solution turned yellow and on evaporation of the solvent gave crystals, m.p. $150-152{ }^{\circ} \mathrm{C}$. On standing the crystals slowly gave off isocyanide. IR ( $\mathrm{KBr})$ : $2175(\mathrm{~s}), 1550$ (s), 1345 (s) $\mathrm{cm}^{-1}$. VS abs. ethanol $(\log \varepsilon): 340(3.2) \mathrm{nm} .{ }^{1} \mathrm{H}$ NMR (60 MHz, CDCl $)$ : $9.39(3 \mathrm{H}, \mathrm{s}), 1.5(36 \mathrm{H}, \mathrm{s})$.

Complex $\mathrm{G}$ was dissolved in a large excess of tert-butyl isocyanide, and left overnight. The solution turned red and white crystals of a copper(I) chloride-tert-butyl isocyanide complex appeared. IR (KBr): $2190 \mathrm{~cm}^{-1}$ (s). ${ }^{1} \mathrm{H}$ NMR $(60 \mathrm{MHz}$, $\mathrm{CDCl}_{3}$ ): 1.52 (s). Elemental analysis gave a Cu:tertbutyl isocyanide ratio of 1:1.5-1:4 on different occasions. The red solution was evaporated by using a water pump at $50{ }^{\circ} \mathrm{C}$ and gave a red oil. The red charge transfer complex was also formed immediately when trinitrobenzene $(10 \mathrm{mmol})$ was dissolved in pure tert-butyl isocyanide $(80 \mathrm{mmol})$, and excess isocyanide removed as above. IR $(\mathrm{KBr})$ : 2180 (s), 1550 (s), 1350 (s) $\mathrm{cm}^{-1}$. VS abs. ethanol $(\log \varepsilon): 495$ (2.25). ${ }^{1} \mathrm{H}$ NMR $\left(60 \mathrm{MHz}, \mathrm{CDCl}_{3}\right)$ : $\delta 9.40(3 \mathrm{H}, \mathrm{s}), 1.52(18 \mathrm{H}, \mathrm{s})$.

Acknowledgements. We thank Dr. T. Olsson for running the NMR spectra and Mr. D. Tanner for checking the English. This work was supported by the Swedish Natural Science Research Council.

\section{REFERENCES}

1. Björklund, C., Nilsson, M. and Wennerström, O. Acta Chem. Scand. 24 (1970) 3599.

2. Björklund, C. and Nilsson, M. Acta Chem. Scand. 22 (1968) 2338.

3. Saegusa, T. and Ito, Y. Synthesis (1975) 291.

4. Nilsson, M., Ullenius, C. and Wennerström, O. Tetrahedron Lett. (1971) 2713.

Acta Chem. Scand. B 34 (1980) No. 2
5. Wennerström, O. Acta Chem. Scand. 25 (1971) 2341.

6. Moberg, C. and Wennerström, O. Acta Chem. Scand. 25 (1971) 2871.

7. Saegusa, T., Yonezawa, K., Murase, I., Konoike, T., Tomita, S. and Ito, Y. J. Org. Chem. 38 (1973) 2319.

8. Saegusa, T., Kobayashi, S., Ito, Y. and Morino, I. Tetrahedron 28 (1972) 3389.

9. Camus, A., Marsich, N., Nardin, G. and Randaccio, L. J. Organomet. Chem. 60 (1973) C39.

10. Day, V. W., Day, R. O., Kristoff, J. S., Hirsekorn, F. J. and Muetterties, E. L. J. Am. Chem. Soc. 97 (1975) 2572.

11. Strauss, M. J. Chem. Rev. 70 (1970) 667.

12. Shein, S. M., Khmelinskaya, A. D. and Brovko, V. V. Chem. Commun. (1969) 1043.

13. Fyfe, C. A. Tetrahedron Lett. (1969) 1521.

14. Olah, G. A. and Mayr, H. J. Org. Chem. 41 (1976) 3448.

15. Malatesta, L. and Bonati, F. Isocyanide Complexes of Metals, Wiley, New York 1969.

16. Ross, S. D. and Labes, M. M. J. Am. Chem. Soc. 79 (1957) 76.

17. Foster, R. and Norris, J. W. J. Chem. Soc. B (1970) 703.

18. Saegusa, T. and Ito, Y. In Ugi, I. Ed., Isonitrile Chemistry, Organic Chemistry, Academic, New York 1971, Vol. 20, Chapter 4.

19. Saegusa, T., Ito, Y., Tomita, S., Kinoshita, H. and Taka-Ishi, N. Tetrahedron 27 (1971) 27.

20. Kuntz, I. D., Jr., Schleyer, P. von R. and Allerhand, A. J. Chem. Phys. 35 (1961) 1533.

21. Otsuka, S., Nakamora, A. and Tatsuno, Y. J. Am. Chem. Soc. 91 (1969) 6994.

22. Saegusa, T., Ito, Y. and Tomita, S. J. Am. Chem. Soc. 93 (1971) 5656.

23. van Koten, G. and Noltes, J. G. Chem. Commun. (1972) 59.

24. Buncel, E., Webb, J. G. K. and Wiltshire, J. F. J. Am. Chem. Soc. 99 (1977) 4429.

25. Ugi, I. and Meyr, R. Chem. Ber. 93 (1960) 239.

26. Knol, D., Koole, N. J. and de Bie, M. J. A. Org. Magn. Reson. (1976) 213.

27. Brewster, R. Q. and Groening, T. Org. Synth. Coll. Vol. 2, (1944) 446.

Received August 17, 1979. 